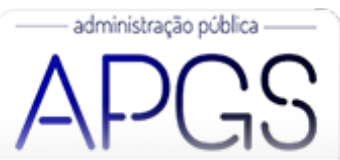

Administração Pública e Gestão Social ISSN: 2175-5787

apgs@ufv.br

Universidade Federal de Viçosa

Brasil

\title{
Governança pública e reeleições municipais em Minas Gerais
}

De Cássio Rodrigues, Alexandre; Braga Rodrigues, Suzana

Governança pública e reeleições municipais em Minas Gerais

Administração Pública e Gestão Social, vol. 12, núm. 1, 2020

Universidade Federal de Viçosa, Brasil

Disponible en: http://www.redalyc.org/articulo.oa?id=351561601008

Esta obra está bajo una Licencia Creative Commons Atribución-NoComercial-SinDerivar 3.0 Internacional. 


\title{
Governança pública e reeleições municipais em Minas Gerais
}

\author{
Public Governance and Municipal Reelections in Minas Gerais \\ Gobernanza Pública y Reelecciones Municipales en Minas Gerais \\ Alexandre De Cássio Rodrigues \\ Centro Universitário Metodista Izabela Hendrix, Brasil \\ alexandrerodrigues.engprod@gmail.com \\ Suzana Braga Rodrigues \\ Universidade FUMEC, Brasil \\ suzana.braga.rodrigues@gmail.com
}

Redalyc: http://www.redalyc.org/articulo.oa? id $=351561601008$

Recepción: 11 Diciembre 2017
Aprobación: 19 Febrero 2018
Publicación: 01 Enero 2020

\section{RESUMo:}

As publicações da Lei de Responsabilidade Fiscal, da Lei da "Ficha Limpa” e da Lei de Acesso à Informação, ocorridas no Brasil nos últimos anos, são exemplos de algumas iniciativas que visam aprimorar a estrutura da governança pública. Paralelamente, tem-se ampliado o debate sobre a continuidade ou extinção do instituto da reeleição de chefes do poder executivo, o qual foi instaurado no país em 1997. Neste contexto, o objetivo deste artigo é analisar a relação entre a governança pública e as reeleições municipais em Minas Gerais em 2016. Fundamentada no modelo da reputação, a primeira hipótese da pesquisa admite que a possibilidade de reeleição influencia os prefeitos a adotarem boas práticas de governança pública. No sentido inverso, baseada na teoria das expectativas racionais, a segunda hipótese considera que prefeitos que adotam boas práticas de governança pública tendem a ser premiados pelo eleitorado com a reeleição. Os resultados dos modelos de regressão multivariada revelam que a possibilidade de reeleição não influencia os prefeitos a adotarem boas práticas de governança, porém, prefeitos que adotam boas práticas de governança tendem a ser reeleitos. A conclusão é que os eleitores, através do voto, selecionam os candidatos à reeleição que mais adotam boas práticas de governança pública, o que reforça os argumentos dos defensores da continuidade do instituto da reeleição. PalaVRas-CHAVE: Governança pública, Reeleições municipais, Modelo da Reputação, Teoria das Expectativas Racionais.

\section{Abstract:}

The publications of the Fiscal Responsibility Law, the "Ficha Limpa" Law and the Access to Information Law, which have taken place in Brazil in recent years, are examples of some initiatives that aim the improvement of the public governance structure. At the same time, the debate on the continuity or extinction of the institute for the reelection of heads of the executive power, which was established in the country in 1997, has been expanded. In this context, the objective of this article is to analyze the relation between public governance and reelections in municipalities in Minas Gerais in 2016. Based on the reputation model, the first research hypothesis admits that the reelection possibility influences the mayors to adopt good practices of public governance. On the other hand, based on the theory of rational expectations, the second hypothesis considers that mayors who adopt good practices of public governance tend to be rewarded by the electorate with reelection. The results of multivariate regression models suggest that the reelection possibility does not influence mayors to adopt good governance practices, but mayors who adopt good governance practices tend to be reelected. The conclusion is that voters select reelection candidates who adopt the best practices of public governance, wich reinforces the arguments of the continuity of the reelection institute.

KEYWORDs: Public Governance, Municipal Reelections, Reputation Model, Rational Expectations Theory.

\section{ReSUMEN:}

Las publicaciones de la Ley de Responsabilidad Fiscal, de la Ley de la "Ficha Limpia" y de la Ley de Acceso a la Información, ocurridas en Brasil en los últimos años, son ejemplos de algunas iniciativas que señalan a mejorar la estructura de la gobernanza pública. Paralelamente, se ha ampliado el debate sobre la continuidad o extinción del instituto de la reelección de jefes del poder ejecutivo, el cual fue instaurado en el país en 1997. En este contexto, el objetivo de este artículo es analizar la relación entre la gobernanza pública y las reelecciones en la mayoría de los municipios de Minas Gerais, en 2016. Fundamentada en el modelo de la reputación, la primera hipótesis de la investigación admite que la posibilidad de reelección influye en los alcaldes a adoptar 
buenas prácticas de gobernanza pública. En el sentido inverso, basado en la teoría de las expectativas racionales, la segunda hipótesis considera que los alcaldes que adoptan buenas prácticas de gobernanza pública tienden a ser premiados por el electorado con la reelección. Los resultados de los modelos de regresión multivariada revelan que la posibilidad de reelección no influye en los alcaldes a adoptar buenas prácticas de gobernanza, pero los alcaldes que adoptan buenas prácticas de gobernanza tienden a ser reelegidos. La conclusión es que los votantes seleccionan a los candidatos a la reelección que más adoptan buenas prácticas de gobierno público, lo que refuerza los argumentos de los defensores de la continuidad del instituto de la reelección.

Palabras clave: Gobernanza pública, Reelecciones municipales, Modelo de la Reputación, Teoría de las Expectativas Racionales.

\section{INTRODUÇÃO}

A análise da relação entre a governança pública e a dinâmica do sistema político é um tema relevante por vários motivos. Primeiramente, segundo a Teoria da Agência (Jensen \& Meckling, 1976), a assimetria de informação e os desequilíbrios de poder e de autoridade entre o principal (a sociedade) e o agente (o governante) podem gerar conflitos de interesses na medida em que o último, para maximizar seus próprios benefícios (reeleger-se), pode contrariar os interesses do primeiro. Assim, para reduzir conflitos, alinhar ações e trazer mais segurança à sociedade, estruturas de governança pública se fazem necessárias (ANAO, 2014; IFAC, 2014; TCU, 2014; OCDE, 2015). Nesse sentido, no Brasil, destacam-se a Lei de Responsabilidade Fiscal, publicada em 2000, que tem por objeto aspectos éticos, morais e de comportamento da liderança; a Lei da "Ficha Limpa", publicada em 2010, que dispõe sobre as condições, motivos e situações que tornam um candidato inelegível a cargo público; e a Lei de Acesso à Informação, publicada em 2011, que facilita o monitoramento e o controle da conduta dos agentes públicos.

Além disso, há que se frisar que a reeleição para chefes do poder executivo no Brasil é um fenômeno relativamente recente, pois somente foi instituída em 1997. Logo, passados cinco mandatos de prefeitos, governadores e presidentes após esta mudança, a literatura ainda carece de compreensão dos reais efeitos da reeleição sobre o comportamento dos gestores públicos e, por consequência, das práticas de governança de seus governos. Outra justificativa para o estudo é que a opinião pública, na maioria das vezes, tem debatido sobre a continuidade ou extinção da reeleição para cargos do poder executivo sem fundamentação empírica suficiente (Cavalcante, 2016).

Neste contexto, o objetivo deste artigo é analisar a relação entre governança pública e reeleição de prefeitos. A investigação concentra-se na eleição de 2016, a mais recente, e em Minas Gerais, o estado brasileiro com o maior número de municípios ( $853,15,3 \%$ do total). Pretende-se responder a duas questóes: i) A possibilidade de serem reeleitos influencia os prefeitos a adotarem boas práticas de governança?; ii) prefeitos que adotam boas práticas de governança são premiados pelos eleitores com a reeleição? No primeiro caso, a hipótese fundamenta-se no modelo de reputação (Besley \& Case, 2003); no segundo, baseia-se na teoria da expectativa racional na explicação do voto (Rogoff, 1990).

A análise dos determinantes da reeleição de prefeitos não é inédita no Brasil. Porém, a literatura enfatiza, sobretudo, a relação entre gestão fiscal e reeleição (Araújo Júnior, Shikida \& Silva, 2003; Mendes \& Rocha, 2004; Araújo Júnior, Cançado \& Shikida, 2005; Meneguim, Bugarim \& Carvalho, 2005; Stranz, Krebs \& Bosseli, 2008; Silva \& Braga, 2013; Cavalcante; 2015). Possivelmente, a governança pública, um conceito mais abrangente que a gestão fiscal (CFA, 2017; TCU, 2014), ainda não foi estudada devido à falta de um índice robusto capaz de mensurá-la (Oliveira \& Pisa, 2015). Contudo, recentemente, o Conselho Federal de Administração (CFA) lançou o Índice de Governança Municipal (IGM), o qual será utilizado neste artigo como proxy da governança pública. Desse modo, esta pesquisa é inovadora, pois analisa o impacto da possibilidade de reeleição de prefeitos sobre a adoção de boas práticas de governança pública e também o inverso, isto é, o efeito da adoção de boas práticas de governança pública sobre a probabilidade de reeleição dos prefeitos. 
Adiante, o artigo discorre sobre a governança pública, o modelo de reputação e a teoria da expectativa racional, os quais fundamentam as hipóteses da pesquisa. Em seguida, apresenta-se as variáveis, mostra-se os modelos econométricos e discute-se os resultados das estimações. Por fim, tem-se as considerações finais.

\section{FUNDAMENTAÇÃO TEÓRICA}

\subsection{GOVERNANÇA PÚBLICA: CONCEITO, PRINCÍPIOS E AVALIAÇÃO}

No contexto da Teoria da Agência, quando as organizações deixaram de ser geridas diretamente por seus proprietários (o principal) e passaram à administração de terceiros (o agente), houve a possibilidade de conflitos de interesses, agravada, sobretudo, pelo fato de o principal não dispor de todas as informações para avaliar o desempenho do agente (Jensen \& Meckling, 1976). Assim, para reduzir os impactos desta assimetria de informações, surgiu a necessidade da governança, um conceito inicialmente aplicado às corporações, que, embora não seja livre de contestações (Secchi, 2009), pode ser entendido como sendo o sistema pelo qual as organizações são dirigidas, monitoradas e incentivadas, o que envolve os relacionamentos entre sócios, conselho de administração, diretoria, órgãos de fiscalização e controle e demais partes interessadas (IBGC, 2015).

O conceito de governança pode ser aplicado às organizações públicas. Neste caso, é a governança pública que determina o equilíbrio de poder entre cidadãos e governantes com o propósito de permitir que o bem comum prevaleça sobre os interesses pessoais (Matias-Pereira, 2010). Desta forma, a governança pública "compreende essencialmente os mecanismos de liderança, estratégia e controle postos em prática para avaliar, direcionar e monitorar a atuação da gestão, com vistas à condução de políticas públicas e à prestação de serviços de interesse da sociedade" (TCU, 2014, p. 26).

Princípios da boa governança pública são apontados por entidades como a Australian National Audit Office (ANAO), a Organização para a Cooperação e Desenvolvimento Econômico (OCDE) e o Internacional Federation of Accountants (IFAC), que, em comum, destacam a transparência (disclosure), a prestação de contas (accountability) e a integridade (compilance). Porém, para ser coerente com a fonte do conceito de governança pública adotado neste trabalho, considera-se os princípios sugeridos pelo Banco Mundial, os quais são utilizados pelo Tribunal de Contas da União (TCU): 
Quadro 1: Princípios da Governança Pública

\begin{tabular}{|c|c|}
\hline Princípio & Conceito/finalidade \\
\hline Legitimidade & $\begin{array}{l}\text { Visa ampliar a incidência do controle externo da } \\
\text { administração para além da aplicação isolada do } \\
\text { critério de legalidade. Não basta verificar se a lei } \\
\text { foi cumprida, mas se o interesse público foi } \\
\text { alcançado. }\end{array}$ \\
\hline Equidade & $\begin{array}{l}\text { É a garantia de que todos tenham acesso ao } \\
\text { exercício de seus direitos civis - liberdade de } \\
\text { expressão, de acesso à informação, de } \\
\text { associação, de voto, igualdade entre gêneros - } \\
\text { politicos e sociais - saúde, educação, moradia e } \\
\text { segurança. }\end{array}$ \\
\hline Responsabilidade & $\begin{array}{l}\text { É o zelo que os agentes de governança devem ter } \\
\text { pela sustentabilidade das organizaçóes, visando } \\
\text { a sua longevidade, incorporando consideraçốes } \\
\text { de ordem social e ambiental na definiçăo de } \\
\text { negócios e operacoóes. }\end{array}$ \\
\hline Eficiência & $\begin{array}{l}\text { É fazer o que é preciso ser feito com a qualidade } \\
\text { adequada ao menor custo possivel. Não se trata } \\
\text { de redução de custo de qualquer maneira, mas } \\
\text { de buscar a melhor relação entre qualidade do } \\
\text { serviço e qualidade do gasto. }\end{array}$ \\
\hline Probidade & $\begin{array}{l}\text { É o dever dos servidores públicos de demonstrar } \\
\text { probidade, zelo, economia e observância às } \\
\text { regras e procedimentos do órgão ao utilizar, } \\
\text { arrecadar, gerenciar e administrar bens e valores } \\
\text { públicos, é a obrigação que os servidores têm de } \\
\text { demonstrar que são dignos de confiança. }\end{array}$ \\
\hline Transparência & $\begin{array}{l}\text { É a possibilidade de acesso a todas as } \\
\text { informaçóes relativas à organização pública, é } \\
\text { um dos requisitos de controle do Estado pela } \\
\text { sociedade civil. A adequada transparência } \\
\text { resulta em um clima de confiança, tanto } \\
\text { internamente quanto nas relaçôes de órgãos e } \\
\text { entidades com terceiros. }\end{array}$ \\
\hline Accountability & $\begin{array}{l}\text { É a obrigação que os agentes têm de prestar } \\
\text { contas de sua atuação de forma voluntária, } \\
\text { assumindo integralmente as consequências de } \\
\text { seus atos e omissóes. }\end{array}$ \\
\hline
\end{tabular}

Fonte: TCU (2014).

Haja vista a complexidade de seus princípios, avaliar a governança pública é um desafio. O Banco Mundial, o Programa das Nações Unidas para o Desenvolvimento e a OCDE publicam índices de governança, mas isto é feito somente para países. No tocante ao Brasil, Oliveira e Pisa (2015) propõem um índice de governança pública fundamentado nos princípios da efetividade, transparência, accountability, participação, equidade, conformidade legal e integridade e ética. Com isso, os autores conseguem mensurar a governança dos estados, Distrito Federal e União, porém reconhecem que a aferição da governança municipal deve ser objeto de novos estudos.

Neste sentido, em dezembro de 2016, o Conselho Federal de Administração (CFA), por meio da Câmara de Gestão Pública, lançou o Índice de Governança Municipal (IGM), uma métrica da governança pública dos municípios brasileiros, que varia de 0 a 1 , sendo melhor quanto maior. O IGM é calculado a partir da média aritmética simples de índices relacionados às dimensões Qualidade da Gestão, Gastos e Finanças Públicas e Desempenho, que também variam entre 0 e 1 , sendo melhores quanto maiores.

Os indicadores que compõem a dimensão Qualidade da Gestão do IGM são expostos no Quadro 2. Em particular, nota-se que essa dimensão agrega ao menos dois princípios da governança pública - transparência e eficiência - pois, respectivamente, examina se o município adota boas práticas de transparência e avalia 
o tamanho da máquina pública em relação ao porte populacional. Cabe ressaltar que, segundo Calderini (2011), a reeleição de prefeitos é influenciada pela eficiência dos gastos públicos.

Quadro 2: Indicadores da dimensão Qualidade da Gestão do IGM

\begin{tabular}{|c|c|c|c|}
\hline Indicador & Objetivo & Cálculo & Polaridade \\
\hline $\begin{array}{l}\text { Terceirização } \\
\text { de serviços } \\
\text { básicos }\end{array}$ & $\begin{array}{l}\text { Verificar se a } \\
\text { oferta de serviços } \\
\text { de saneamento é } \\
\text { feita por empresas } \\
\text { terceirizadas }\end{array}$ & $\begin{array}{l}\text { Variáveis binárias } \\
\text { em que } 1 \text { equivale } \\
\text { a sime } 0 \text { a não }\end{array}$ & Maior-melhor \\
\hline Informatização & $\begin{array}{l}\text { Averiguar se as } \\
\text { prefeituras } \\
\text { possuem sistemas } \\
\text { informatizados }\end{array}$ & $\begin{array}{l}\text { Variáveis binárias } \\
\text { em que } 1 \text { equivale } \\
\text { a sime } 0 \text { a não }\end{array}$ & Maior-melhor \\
\hline $\begin{array}{l}\text { Articulação } \\
\text { institucional }\end{array}$ & $\begin{array}{l}\text { Identificar se o } \\
\text { município participa } \\
\text { de consórcios } \\
\text { públicos nas áreas } \\
\text { de educação, } \\
\text { saúde, turismo, } \\
\text { meio ambiente, etc. }\end{array}$ & $\begin{array}{l}\text { Variáveis binárias } \\
\text { em que } 1 \text { equivale } \\
\text { a sime } 0 \text { a não }\end{array}$ & Maior-melhor \\
\hline $\begin{array}{l}\text { Planejamento } \\
\text { urbano }\end{array}$ & $\begin{array}{l}\text { Apurar se o } \\
\text { municipio dispõe } \\
\text { de legislação sobre } \\
\text { planejamento } \\
\text { urbano }\end{array}$ & $\begin{array}{l}\text { Variáveis binárias } \\
\text { em que } 1 \text { equivale } \\
\text { a sime } 0 \text { a não }\end{array}$ & Maior-melhor \\
\hline Transparência & $\begin{array}{l}\text { Examinar se o } \\
\text { municipio adota } \\
\text { boas práticas de } \\
\text { transparência }\end{array}$ & $\begin{array}{l}\text { Variáveis binárias } \\
\text { em que } 1 \text { equivale } \\
\text { a sime } 0 \text { a não, de } \\
\text { acordo com itens } \\
\text { avaliados pelo } \\
\text { Ministério Público } \\
\text { Federal }\end{array}$ & Maior-melhor \\
\hline Servidores & $\begin{array}{l}\text { A ferir a proporção } \\
\text { de servidores em } \\
\text { relação ao } \\
\text { tamanho da } \\
\text { população }\end{array}$ & $\begin{array}{l}\text { Razão entre o } \\
\text { número de } \\
\text { servidores e } \\
\text { populaçấo }\end{array}$ & Menor-melhor \\
\hline Comissionados & $\begin{array}{l}\text { Medir a proporção } \\
\text { de servidores } \\
\text { comissionados no } \\
\text { total de servidores }\end{array}$ & $\begin{array}{l}\text { Razão entre o } \\
\text { número de } \\
\text { servidores } \\
\text { comissionadose } \\
\text { total de servidores }\end{array}$ & Menor-melhor \\
\hline
\end{tabular}

Fonte: CFA (2017, adaptado).

O Quadro 3 mostra os indicadores que compõem a dimensão Gastos e Finanças Públicas do IGM. Em síntese, essa dimensão captura o comprometimento do gestor com as áreas sociais em detrimento das demais funções governamentais, como também verifica a disciplina e a qualidade da gestão orçamentária e financeira. Tais fatores, conforme salienta Cavalcante (2015), relacionam-se positivamente com a chance de reeleição dos prefeitos e, também, podem ser afetados por ela. 
Quadro 3: Indicadores da dimensão Gastos e Finanças do IGM

\begin{tabular}{|c|c|c|c|}
\hline Indicador & Objetivo & Cálculo & Polaridade \\
\hline $\begin{array}{l}\text { Gasto per } \\
\text { capita em } \\
\text { saúde e } \\
\text { educação }\end{array}$ & $\begin{array}{l}\text { Medir o grau de } \\
\text { investimento em } \\
\text { saúde e educação }\end{array}$ & $\begin{array}{l}\text { Razão entre os } \\
\text { gastos nestas } \\
\text { áreas e população }\end{array}$ & Maior-melhor \\
\hline $\begin{array}{l}\text { Índice } \\
\text { Federação } \\
\text { das } \\
\text { Indústrias } \\
\text { do Estado } \\
\text { do Rio de } \\
\text { Janeiro } \\
\text { (Firjan) de } \\
\text { Gestăo } \\
\text { Fiscal }\end{array}$ & $\begin{array}{l}\text { Mensurar a } \\
\text { disciplina e a } \\
\text { qualidade da } \\
\text { gestão } \\
\text { orçamentária e } \\
\text { financeira }\end{array}$ & $\begin{array}{l}\text { Média ponderada } \\
\text { de indicadores } \\
\text { relativos à receita } \\
\text { própria, gastos } \\
\text { com pessoal, } \\
\text { investimentos, } \\
\text { liquidez e custo da } \\
\text { divida }\end{array}$ & Maior-melhor \\
\hline
\end{tabular}

Por sua vez, o Quadro 4 destaca os indicadores da dimensão Desempenho do IGM, os quais se associam principalmente ao princípio da equidade da governança pública. 
Quadro 4: Indicadores da dimensão Desempenho do IGM

\begin{tabular}{|c|c|c|c|}
\hline Indicador & Objetivo & Cálculo & Polaridade \\
\hline $\begin{array}{l}\text { Qualidade } \\
\text { habitacional }\end{array}$ & $\begin{array}{l}\text { Mensurar o } \\
\text { percentual da } \\
\text { população que tem } \\
\text { acesso a água } \\
\text { encanada, } \\
\text { banheiro e coleta } \\
\text { de lixo }\end{array}$ & $\begin{array}{l}\text { Razão entre a } \\
\text { população que } \\
\text { vive em domicilios } \\
\text { com acesso a } \\
\text { serviços básicos e } \\
\text { populaçấo total }\end{array}$ & Maior-melhor \\
\hline Vulneralibilidade & $\begin{array}{l}\text { Analisar o grau de } \\
\text { vulnerabilidade da } \\
\text { população }\end{array}$ & $\begin{array}{l}\text { Razão entre o } \\
\text { número de cada } \\
\text { grupo vulnerável e } \\
\text { o total do grupo } \\
\text { sema } \\
\text { característica de } \\
\text { vulnerabilidade } \\
\end{array}$ & Menor-melhor \\
\hline $\begin{array}{l}\text { Atendimento } \\
\text { médico }\end{array}$ & $\begin{array}{l}\text { Mensurar a } \\
\text { proporção de } \\
\text { médicos e de } \\
\text { consultas em } \\
\text { atenção básica à } \\
\text { saúde }\end{array}$ & $\begin{array}{l}\text { Razão entre } \\
\text { número de } \\
\text { consultas (e } \\
\text { médicos) e } \\
\text { população }\end{array}$ & Maior-melhor \\
\hline Educação & $\begin{array}{l}\text { Mensurar o } \\
\text { percentual de } \\
\text { crianças que estão } \\
\text { na escola ou creche }\end{array}$ & $\begin{array}{l}\text { Razão entre o } \\
\text { número de } \\
\text { crianças de 0 a } 5 \\
\text { anos que estão na } \\
\text { escola e total de } \\
\text { crianças daquela } \\
\text { faixa etária }\end{array}$ & Maior-melhor \\
\hline $\begin{array}{l}\text { Mortalidade } \\
\text { infantil }\end{array}$ & $\begin{array}{l}\text { Obter um } \\
\text { panorama da } \\
\text { saúde pública }\end{array}$ & $\begin{array}{l}\text { Número de } \\
\text { crianças que não } \\
\text { sobrevivem até o } \\
\text { primeiro ano de } \\
\text { vida a cada } 1000 \\
\text { nascimentos }\end{array}$ & Menor-melhor \\
\hline IDHM & $\begin{array}{l}\text { Avaliar o nivel de } \\
\text { desenvolvimento } \\
\text { humano municipal }\end{array}$ & $\begin{array}{l}\text { Média geométrica } \\
\text { das dimensőes } \\
\text { renda, longevidade } \\
\text { e educaçấo }\end{array}$ & Maior-melhor \\
\hline
\end{tabular}

$$
\text { Fonte: CFA (2017, adaptado). }
$$

Apresentados o conceito, os princípios e as formas de avaliação da governança pública, adiante, com base no modelo da reputação e na teoria das expectativas racionais, fundamentam-se as hipóteses que relacionam a governança pública às reeleições de prefeitos.

\subsection{O MODELO DA REPUTAÇÃO E A TEORIA DAS EXPECTATIVAS RACIONAIS}

O instituto da reeleição no sistema eleitoral brasileiro foi introduzido pela emenda constitucional número 16, de 04 de junho de 1997. Com isso, os chefes do poder executivo passaram a ter o direito de disputar a reeleição para a mesma função, para um único mandato, e no exercício do cargo. Desde então, já foram realizadas cinco eleições para presidente da República, governadores e prefeitos. Em meio aos debates sobre as consequências políticas e institucionais da reeleição, tanto na academia quanto entre os decisores políticos, em maio de 2017, a Câmara dos Deputados instalou uma comissão especial para analisar uma proposta de emenda à constituição que acaba com a reeleição para cargos do poder executivo. 
Os contrários à reeleição argumentam que esta medida fere os princípios de alternância do poder e, principalmente, interfere nas condições de equidade da competição eleitoral. Afinal, a possibilidade de reeleição motivaria os candidatos que podem se reeleger a utilizar a máquina pública para obter sucesso eleitoral (Brambor \& Cenviva, 2012), ou seja, a reeleição seguiria uma lógica oportunista, haja vista a suposição de irracionalidade dos eleitores (Nordhaus, 1975). Neste contexto, o modelo de reputação (reputation model), proposto por Besley e Case (2003), ressalta a importância da credibilidade do governante perante os eleitores. Isso porque quando o governante tem possibilidade de manter-se no cargo por mais um mandato, prevalece a percepção de que ele possui mais incentivos para se alinhar às preferências do eleitorado (adotando práticas de boa governança pública, por exemplo), pois isso facilitaria a consecução do objetivo de reeleger-se. Por outro lado, este comportamento não seria observado em governantes em segundo mandato, uma vez que a limitação de apenas uma reeleição tenderia a diminuir a motivação deles em adotar boas práticas de governança pública. Logo, a primeira hipótese desta pesquisa é:

H1: A possibilidade de reeleição influencia os prefeitos a adotarem boas práticas de governança pública.

Por outro lado, os defensores da reeleição sustentam que um único mandato limita a capacidade de realização do governo, estimula a descontinuidade administrativa e despreza a experiência acumulada pelo chefe do executivo. Especialmente, alegam que a reeleição pode ser uma forma de aperfeiçoar a capacidade decisória dos eleitores, pois permite-lhes punir ou premiar os políticos de acordo com a performance deles. Em outras palavras, a reeleição funcionaria como uma espécie de accountability dos governantes (Brambor \& Cenviva, 2012). De acordo com a teoria das expectativas racionais (Rogoff, 1990), o governante somente consegue se reeleger se a sua competência (expressa por meio da adoção de boas práticas de governança, por exemplo) estiver acima de um nível mínimo esperado pelos eleitores racionais, já que eles, mesmo diante de um cenário de assimetria de informaçóes, utilizariam todo o conhecimento disponível para prever a competência ótima do candidato. Diante disso, a segunda hipótese desta pesquisa é:

H2: Prefeitos que adotam boas práticas de governança pública tendem a ser premiados pelo eleitorado com a reeleição.

Nas duas seções seguintes testa-se as hipóteses supracitadas. Com isso, pretende-se contribuir para a compreensão da relação entre governança pública e reeleições para prefeitos, uma temática atual que, embora seja de suma importância, ainda é pouco explorada pela literatura.

\section{A POSSIBILIDADE DE REELEIÇÃO INFLUENCIA A GOVERNANÇA PÚBLICA?}

Esta seção dedica-se a testar a primeira hipótese da pesquisa: Dada a possibilidade de reeleição, prefeitos em primeiro mandato tendem a adotar boas práticas de governança pública. Logo, a variável dependente é a governança pública, cujo proxy é o Índice de Governança Municipal (IGM), referente a 2015, o único disponível, que foi coletado no sítio eletrônico do Conselho Federal de Administração.

Dentre as variáveis independentes, a principal é a possibilidade de o prefeito se reeleger, denominada “poss_reel”, que assume o valor 1 caso o prefeito esteja em primeiro mandato e 0, caso esteja em segundo mandato. Assim, de acordo com o modelo da reputação, espera-se que sejam observadas melhores práticas de governança pública em governos de prefeitos em primeiro mandato.

Ainda quanto ao aspecto político, para explicar a governança pública, considera-se a variável força política, que é medida pelo percentual de votos que o prefeito obteve no pleito anterior, ocorrido em 2012. Esperase que quanto maior for a força política, maior será o patrimônio eleitoral do governante e, portanto, menor deverá ser a preocupação dele com a performance do seu governo (Mendes \& Rocha, 2004), em termos de governança pública.

O alinhamento partidário entre governantes de diferentes esferas é um fator que pode influenciar a implementação de políticas públicas (Cavalcante, 2016; Novaes \& Mattos, 2010) e, consequentemente, a governança pública. Assim, o modelo incorpora a variável dicotômica PT, que verifica o alinhamento do 
partido do prefeito ao partido do governador de Minas Gerais e da presidente da República, que, em 2015, era o Partido dos Trabalhadores (PT). Todos os dados das variáveis políticas foram extraídos do sítio do Tribunal Superior Eleitoral (TSE).

Além disso, o modelo engloba variáveis de controle socioeconômicas (produto interno bruto - PIB - per capita) e demográficas (tamanho da população - pop), as quais podem também impactar a implementação de políticas públicas (Silva \& Braga, 2013), e, por conseguinte, a governança pública. Os dados dessas variáveis foram coletados no sítio do Instituto Brasileiro de Geografia e Estatística (IBGE).

A amostra contemplou 525 dos 853 municípios de Minas Gerais, para os quais se dispunha de dados de todas as variáveis. Devido à falta de simetria e ao peso das caudas da distribuição das variáveis independentes contínuas (força eleitoral, PIB per capita e população), foi tomado o logaritmo delas, o que, como pode ser verificado no Apêndice, solucionou o problema. Desta forma, estimou-se o modelo dado pela equação (1):

$$
\begin{aligned}
& \left.I G M=\beta_{0}+\beta_{\text {poss_ree }}+\beta_{2} \ln (\text { força eleitord })\right]+\beta_{3} P T_{i}+ \\
& \beta_{4} \ln \left(\text { PIBpercapit } \phi_{1}+\beta_{5} \ln (\text { pop })_{i}+\varepsilon_{i}\right.
\end{aligned}
$$

Os resultados das estimações são mostrados na Tabela 1. Observa-se que a significância global da regressão está garantida, conforme a estatística F. Também não se verificam problemas de autocorrelação dos resíduos, uma vez que a estatística d, de Durbin-Watson, foi estimada em 2,113 . O coeficiente $\mathrm{R}^{2}$ ajustado, cotado em 0,501 , indica que $50,1 \%$ das variações do IGM podem ser explicadas pelas variáveis independentes. Outros testes realizados relevaram não haver problemas de colinearidade, endogeneidade ou heterocedasticidade.

Tabela 1: Efeitos sobre a governança pública

\begin{tabular}{lllll}
\hline Variável & Coeficiente & Erro-padrão & Estatística t & Valor $\mathbf{p}$ \\
\hline Constante & 0,291 & 0,048 & 6,035 & 0,000 \\
Possibilidade de reeleição & 0,000 & 0,005 & 0,033 & 0,974 \\
Força eleitoral & $-0,022$ & 0,010 & $-2,169$ & 0,031 \\
Partido governador/presidenta & $-0,001$ & 0,010 & $-0,088$ & 0,930 \\
PIB per capita & 0,061 & 0,004 & 16,133 & 0,000 \\
População & 0,016 & 0,002 & 7,413 & 0,000 \\
\hline Estatística F & & & 106,00 & 0,000 \\
Estatística d (Durbin-Watson) & & & 2,113 & \\
$\mathrm{R}^{2}$ ajustado & & 0,501 & \\
\hline
\end{tabular}

Fonte: Elaboração dos autores.

Comentados os indicadores econométricos, passa-se à discussão da significância e do sinal dos coeficientes estimados. Analisando-se os resulados da Tabela 1, nota-se que, ao nível de 5\% de significância, o coeficiente da principal variável independente, que indica a possibilidade de reeleição do prefeito, não é significativo, o que leva à refutação da primeira hipótese da pesquisa. Isso quer dizer que não há diferença entre a governança pública de governos de prefeitos em primeiro ou em segundo mandato. Este resultado se assemelha ao obtido por Cavalcante (2016), que concluiu que a expectativa de reeleição não afeta a gestão fiscal dos municípios. Possivelmente, a evidência encontrada neste trabalho está relacionada às estruturas de governança recentemente implantadas na administração pública, especialmente a Lei de Responsabilidade Fiscal, que restringem as ações de todos os prefeitos.

As evidências empíricas também apontam que quanto maior a força eleitoral do prefeito, menor é a governança pública. Uma explicação para isso é quando o governante possui um grande patrimônio eleitoral, o que pode favorecê-lo em uma eventual disputa de recondução ao cargo, ele tem menos incentivos para adotar boas práticas de governança. Verifica-se ainda que o alinhamento entre o partido do prefeito e o partido dos chefes do poder executivo das esferas superiores não influencia a governança pública. Com relação 
às variáveis de controle socioeconômico e demográfico, conforme esperado, quanto mais rico e populoso é o município, maior tende a ser a governança pública.

\section{A gOVERNANÇA PÚBLICA INFLUENCIA A REELEIÇÃo?}

Nesta seção, testa-se a segunda hipótese da pesquisa: Prefeitos que adotam boas práticas de governança tendem a ser premiados pelo eleitorado com a reeleição. Então, a variável dependente é a reeleição do governante municipal (reeleito), a qual é representada por uma dummy, que assume o valor 0 quando o prefeito em primeiro mandato se candidatou à reeleição e perdeu e 1 , quando o prefeito em primeiro mandato se candidatou à reeleição e venceu.

Para explicar a reeleição dos prefeitos, a principal variável é a governança pública, que é representada pelo IGM. Considerando a teoria das expectativas racionais, espera-se que prefeitos cujos governos adotem boas práticas de governança tenham maior probabilidade de serem reeleitos.

Como na seção anterior, incorporam-se variáveis políticas, socioeconômicas e demográficas. Assim, já que representa o patrimônio eleitoral do governante, espera-se que a força política influencie positivamente a reeleição dele. Quanto ao alinhamento entre os partidos do prefeito aos partidos do governador e do presidente, optou-se por fazer uma estratificação. O motivo disso foi o impeachment da presidenta Dilma Rousseff, acontecido em 31 de agosto de 2016, que pode ter impactado nos resultados das eleições municipais ocorridas em outubro daquele ano. Desse modo, além da variável dummy PT, consideraram-se as variáveis "PMDB" e "PSDB", que, respectivamente, indicam o alinhamento do partido do prefeito ao partido do sucessor da presidenta impedida (o Partido do Movimento Democrático Brasileiro, PMDB) e ao partido do principal adversário dela nas eleições de 2014 (o Partido da Social Democracia Brasileira, o PSDB). Logo, espera-se que, em consequência do impeachment, prefeitos filiados ao PT tenham menor probabilidade de serem reeleitos, diferentemente do que é esperado daqueles filiados ao PMDB ou PSDB.

Um ponto importante a se frisar que é embora Cavalcante (2016, p. 320) afirme que "os recursos da campanha eleitoral para prefeito, sem dúvida, constituem um fator crucial para a compreensão do sucesso dos candidatos", o modelo proposto pelo autor não considera o impacto do dinheiro sobre o desempenho eleitoral. Entretanto, haja vista a disponibilidade, no sítio do TSE, dos recursos empregados pelos candidatos a prefeitos nas eleições de 2016, decidiu-se incluir no modelo a variável gasto. Tal iniciativa torna o modelo ainda mais robusto porque a disputa eleitoral daquele ano foi a primeira em que a lei, além de fixar o limite máximo de gastos nas campanhas eleitorais, permitiu apenas o financiamento por pessoas físicas, vetando, portanto, as doações de empresas, permitidas até então (Brasil, 2015). Diante disso, a variável gasto é a razão entre as despesas contratadas pelo candidato à reeleição e o limite de gastos permitido pela legislação.

A amostra contemplou 248 dos 405 prefeitos de Minas Gerais que se candidataram a reeleição em 2016. A exclusão dos demais se deu porque os candidatos tiveram candidatura indeferida com base na Lei da "Ficha Limpa" ou porque algum dos dados das variáveis de interesse não estava disponível. Como no modelo 1, devido à falta de simetria e ao peso das caudas da distribuição das variáveis independentes contínuas (força eleitoral, PIB per capita, população e gasto), foi tomado o logaritmo delas, o que resolveu o problema, conforme pode ser verificado no Apêndice. Na estimação dos coeficientes do modelo (equação 2), adotou-se a regressão logit, uma das mais indicadas quando a variável dependente é binária (Wooldrige, 2006).

$$
\begin{aligned}
& \text { Reeleito }=\beta_{0}+\beta_{1} I G M_{i}+\beta_{2} \ln (\text { força_eleitora })_{i}+\beta_{3} P T_{i}+\beta_{4} P M D B+ \\
& +\beta_{6} P S B D_{1}+\beta_{7} \ln (\text { PIB percapitd })_{i}+\beta_{8} \ln (\text { pop })_{i}+\beta_{9} \ln (\text { gasto })_{i}+\varepsilon_{i}
\end{aligned}
$$

Os resultados das estimações são mostrados na Tabela 2. Nota-se que o modelo estimado prevê corretamente $62,9 \%$ da classificação dos prefeitos em reeleito ou não. Outros testes realizados relevaram não haver problemas de colinearidade, endogeneidade ou heterocedasticidade. 
Tabela 2: Efeitos sobre a reeleição de prefeitos

\begin{tabular}{lllll}
\hline Variável & Coeficiente & Erro-padrão & Odds ratio & Valor p \\
\hline Constante & 4,611 & 3,328 & 100,542 & 0,116 \\
IGM - governança pública & 6,479 & 3,092 & 651,563 & 0,036 \\
Força eleitoral & 0,102 & 0,615 & 1,107 & 0,869 \\
PT & $-2,172$ & 0,795 & 0,114 & 0,006 \\
PMDB & $-2,259$ & 0,338 & 0,771 & 0,443 \\
PSDB & $-0,267$ & 0,391 & 0,766 & 0,495 \\
PIB per capita & 0,400 & 0,360 & 1,492 & 0,266 \\
População & $-0,628$ & 0,170 & 0,534 & 0,000 \\
Gasto & 0,627 & 0,213 & 1,871 & 0,003 \\
\hline \%de previsões corretas & 62,9 & & \\
Pseudo R & 0,166 & & & \\
\hline
\end{tabular}

Fonte: Elaboração dos autores.

Ainda se observa, ao nível de $5 \%$ de significância, que a governança pública, a principal variável independente, afeta positivamente a reeleição dos prefeitos, o que confirma a segunda hipótese da pesquisa. Objetivamente, o odds ratio dessa variável $(651,563)$ indica que o incremento de 0,01 no IGM implica no aumento em cerca de seis vezes da probabilidade de o prefeito ser reeleito. Isso é um indício de que, mesmo havendo assimetria de informações, os eleitores conseguem avaliar os candidatos, reelegendo aqueles que mais adotam boas práticas de governança. Nesse sentido, é realçada a importância de estruturas de governança como a Lei de Acesso à Informação, a qual facilita o monitoramento e o controle da conduta dos prefeitos.

Com relação às variáveis políticas, nota-se que a força eleitoral não altera a reeleição dos prefeitos. Este resultado contraria as conclusões obtidas por Cavalcante (2016), que investigou o impacto da margem de vitória no pleito anterior sobre os resultados das eleições para prefeitos em 2000, 2004, 2008 e 2012. A evidência encontrada nesta pesquisa pode estar relacionada ao aperfeiçoamento da capacidade decisória dos eleitores, pois um bom desempenho de um candidato em uma eleição não é garantia de sucesso na eleição seguinte, o que importa são as práticas de governança adotadas por ele. Além disso, conforme esperado, nota-se que prefeitos filiados ao PT têm menor probabilidade de serem reeleitos. Mais especificamente, ser filiado ao PT reduz a chance de reeleição em 88,6\% (1 - 0,114=0,886), ou seja, aparentemente, os eleitores penalizam nas urnas candidatos cujos partidos estejam envolvidos em casos de corrupção ou de improbidade administrativa. Contudo, divergindo das expectativas, ser filiado ao PMDB ou PSBD não impacta na probabilidade de reeleição.

Tem-se ainda que o PIB per capita não influencia a reeleição dos prefeitos, resultado que é condizente com conclusão de Silva e Braga (2013), que analisaram os determinantes da reeleição municipal da Bahia para o período de 2000 a 2008. Todavia, quanto maior a população, menor é chance de reeleição dos prefeitos. Em outras palavras, em municípios menos populosos, a probabilidade de os prefeitos serem reeleitos é maior, o que pode ser explicado pelo fato de que, nestes, a concorrência é menor, pois, em geral, o número de candidatos é pequeno. Constata-se também que quanto maior o gasto em campanha em relação ao limite permitido pela legislação, maior é a probabilidade de reeleição dos prefeitos, o que reafirma as conclusões de Speck e Cervi (2016) sobre a importância do dinheiro para o sucesso eleitoral de candidatos a prefeito.

Ainda que interessantes, os resultados anteriores podem apresentar viés de seleção, pois podem ter concorrido à reeleição justamente os prefeitos cujos governos adotaram boas práticas de governança, o que, naturalmente, aumentaria a probabilidade de recondução destes governantes ao cargo. Desse modo, para verificar um possível efeito de viés de seleção, assim como fizeram Mendes e Rocha (2004), recorreu-se ao modelo de dois estágios proposto por Heckman (1979). A ideia desse modelo é estimar duas equações conjuntamente, sendo que a primeira avalia a probabilidade de o prefeito se candidatar à reeleição (Equação 3; regressão logit) e a segunda mede as chances de sucesso levando em conta a decisão de disputar a reeleição (Equação 4, que é idêntica à Equação 2): 


$$
\begin{aligned}
& \text { Cand }=\beta_{0}+\beta_{1} I G M_{i}+\beta_{2} \ln (\text { força_eleitora })_{i}+\beta_{3} P T_{i}+ \\
& \beta_{4} \ln \left(\text { PIBpercapitd } d_{i}+\beta_{5} \ln (\text { pop })_{i}+\eta_{i}\right.
\end{aligned}
$$

Neste caso, supõe-se que $\eta$ i e $\varepsilon$ i tenham distribuição normal bivariada com média 0 e variância 1 , havendo correlação $\rho$ entre os erros. Caso $\rho$ seja maior que zero, então os mesmos fatores não considerados no modelo que aumentariam (diminuiriam) a probabilidade de candidatura também aumentariam (diminuiriam) a probabilidade de reeleição, relevando, assim, um viés de seleção. Por outro lado, se $\rho$ for igual a zero, não há viés de seleção, o que implica que as equações de candidatura e reeleição são independentes e, portanto, podese apenas estimar a equação de reeleição, como foi feito anteriormente.

$\mathrm{Na}$ estimação da equação de candidatura a amostra contemplou 424 dos 684 prefeitos de Minas Gerais que podiam se candidatar à reeleição em 2016. A exclusão dos demais se deu porque os candidatos tiveram candidatura indeferida com base na Lei da "Ficha Limpa" ou porque algum dos dados das variáveis de interesse não estava disponível. Como nos casos anteriores, devido à falta de simetria e ao peso das caudas da distribuição das variáveis independentes contínuas (força eleitoral, PIB per capita e população), foi tomado o logaritmo delas, o que resolveu o problema, conforme pode ser verificado no Apêndice.

Os resultados da estimação da equação de candidatura são mostrados na Tabela 3. Nota-se, ao nível de $5 \%$ de significância, que somente a força eleitoral é importante para explicar a decisão do prefeito em se candidatar à reeleição. Ou seja, conforme esperado, quanto maior é o patrimônio eleitoral do político, maior é a probabilidade de ele disputar a recondução ao cargo. Particularmente, não foram encontradas evidências de que a adoção de boas práticas de governança influencie o prefeito a concorrer à reeleição. Isso possivelmente está atrelado ao fato de estruturas de governança, como a Lei da "Ficha Limpa", impedirem que agentes públicos que não adotem boas práticas de governança, sobretudo com relação ao cumprimento da Lei de Responsabilidade Fiscal, possam se candidatar a cargos públicos.

Tabela 3: Efeitos sobre a candidatura de prefeitos - modelo de seleção de Heckman

\begin{tabular}{llll}
\hline Variável & Coeficiente & Erro-padrão & Valor p \\
\hline Constante & $-2,621$ & 1,590 & 0,099 \\
IGM - governança pública & 1,151 & 1,373 & 0,402 \\
Força eleitoral & 0,751 & 0,337 & 0,026 \\
PT & 0,240 & 0,290 & 0,407 \\
PIB per capita & $-0,133$ & 0,142 & 0,350 \\
População & $-0,043$ & 0,071 & 0,549 \\
\hline \%de previsões corretas & 59,9 & & \\
Pseudo R & 0,025 & & \\
\hline
\end{tabular}

Fonte: Elaboração dos autores.

$s$ resultados da estimação da equação de reeleição são mostrados na Tabela 4. Primeiramente, nota-se, ao nível de $5 \%$ de significância, que a correlação entre os erros das equações estimadas - $p$ - não é significativa, ou seja, não há evidências para refutar a hipótese de que $\rho$ seja nula. Esse resultado confirma que as duas equações estimadas são independentes, isto é, o que facilita (dificulta) a candidatura não facilita (dificulta) a reeleição. Por sinal, enquanto somente a força eleitoral é determinante para explicar a candidatura (Tabela 3), se fosse adotado o modelo de seleção, a reeleição seria determinada somente pelo gasto em campanha em relação ao limite permitido pela legislação (Tabela 4). 
Tabela 4: Efeitos sobre a reeleição de prefeitos - modelo de seleção de Heckman

\begin{tabular}{llll}
\hline Variável & Coeficiente & Erro-padrão & Valor $\mathbf{p}$ \\
\hline Constante & $-2,244$ & 12,588 & 0,859 \\
IGM - governança pública & 2,151 & 3,656 & 0,556 \\
Força eleitoral & 0,659 & 2,371 & 0,781 \\
PT & 0,523 & 0,750 & 0,485 \\
PMDB & 0,057 & 0,092 & 0,537 \\
PSDB & 0,034 & 0,110 & 0,753 \\
PIB per capita & $-0,001$ & 0,430 & 0,999 \\
Populaçăo & $-0,152$ & 0,147 & 0,301 \\
Gasto & $-0,129$ & 0,054 & 0,018 \\
\hline $\boldsymbol{p}$ & $\mathbf{0 , 8 8 9}$ & $\mathbf{5 , 4 9 9}$ & $\mathbf{0 , 8 7 2}$ \\
\hline
\end{tabular}

Fonte: Elaboração dos autores.

Em suma, o modelo de seleção não se mostrou adequado para analisar o fenômeno de reeleições de prefeitos em Minas Gerais, pois não foi identificado viés de seleção. Logo, pode-se estimar apenas a equação de reeleição, o que tornam válidos os resultados apresentados no início desta seção.

\section{CONSIDERAÇÕES FINAIS}

Este artigo analisou a relação entre governança pública e reeleição de prefeitos em Minas Gerais, o que foi feito a partir de duas hipóteses: A possibilidade de reeleição influencia os prefeitos a adotarem boas práticas de governança e os eleitores tendem a premiar com a reeleição prefeitos que adotam boas práticas de governança.

A primeira hipótese foi refutada, o que indica que não foram encontradas evidências de que exista diferença entre a governança em governos de prefeitos que podem se candidatar à reeleição e naqueles cujos prefeitos não podem fazê-lo devido à restrição imposta pela legislação em vigor. Isso pode ser um indício de que as recentes estruturas de governança implementadas na administração pública brasileira possam ser, de fato, eficazes, pois, mesmo impedidos de candidatar-se à reeleição, os prefeitos em segundo mandato adotam práticas de governança similares aos prefeitos em primeiro mandato, os quais, de acordo com o modelo da reputação, teriam mais incentivos para fazê-lo.

Já a segunda hipótese foi confirmada, o que indica que prefeitos que adotam boas práticas de governança tendem a ser reeleitos, sobretudo em municípios menos populosos e mais pobres. Uma possível interpretação deste fato é que, embora haja assimetria de informações, os eleitores, racionalmente, conseguem avaliar o governante, punindo com a derrota nas urnas aqueles que não praticam boa governança. Isso, somado ao resultado anterior, reforça os argumentos dos defensores da continuidade do instituto da reeleição, pois, por um lado, aparentemente, as estruturas de governança, notadamente a legislação, impedem que a reeleição siga uma lógica oportunista e, por outro, os eleitores, através do voto, selecionam os candidatos à reeleição que mais adotam boas práticas de governança pública.

A extensão desta pesquisa a todos os municípios brasileiros é um interessante caminho para generalizar as conclusões aqui encontradas. Além disso, trabalhos futuros poderão investigar se a adoção de práticas de boa governança varia entre os mandatos de prefeitos que foram reeleitos, o que contribuiria para melhor compreender o efeito da reputação. Isso requer que sejam conhecidos os índices de governança municipal para vários anos. Como esses estavam disponíveis somente para 2015, não foi possível tratar daquela problemática nesta pesquisa. 


\section{REFERÊNCIAS}

ANAO - Australian National Audit Office. Public Sector Governance: Strengthening Performance Through Good Governance. 2014.

ARAUJO JUNIOR, A. F.; CANÇADO, P. L.; SHIKIDA, Cláudio Djissey. Economics and politics: o que determina as chances de reeleição em municípios? O caso das eleições municipais de Minas Gerais-2000. Informe Gepec, Toledo, v. 9, n. 2, 2005.

ARAÚJO JR, A.; SHIKIDA, C.; SILVA, M. Federalismo fiscal, ciclos políticos e reeleição: uma breve análise do caso mineiro. Perspectiva econômica, v. 38, n. 122, p. 5-20, 2003.

BESLEY, Timothy; CASE, Anne. Political institutions and policy choices: evidence from the United States. Journal of Economic Literature, v. 41, n. 1, p. 7-73, 2003.

BRASIL. Lei n. ${ }^{\circ}$ 13.165, de 29 de setembro de 2015. Altera as Leis nos 9.504, de 30 de setembro de 1997, 9.096, de 19 de setembro de 1995, e 4.737, de 15 de julho de 1965 - Código Eleitoral, para reduzir os custos das campanhas eleitorais, simplificar a administração dos Partidos Políticos e incentivar a participação feminina. Diário Oficial da União, Brasília, 29 set. 2015.

BRAMBOR, Thomas; CENEVIVA, Ricardo. Reeleição e continuísmo nos municípios brasileiros. Novos EstudosCEBRAP, n. 93, p. 09-21, 2012.

CALDERINI, Sérgio Ricardo. Três ensaios sobre o gasto local no Brasil: descentralização, eficiência e voto. Tese (Doutorado em Administração Pública e Governo). Fundação Getúlio Vargas, 2011.

CFA - Conselho Federal de Administração. Metodologia do Índice CFA de Governança Municipal. 2017. Disponível em: . Acesso em: 20 maio 2017.

CAVALCANTE, Pedro. Vale a pena ser um bom prefeito? Comportamento eleitoral e reeleição no Brasil. Opinião Pública, v. 21, n. 1, p. 87-104, 2015.

. Desempenho fiscal e eleições no Brasil: uma análise comparada dos governos municipais. Revista de Administração Pública, v. 50, n. 2, p. 307-330, 2016.

IBCG - Instituto Brasileiro de Governança Corporativa. Guias das melhores práticas de governança corporativa para fundaçôes e institutos empresariais. 2015.

IFAC - Internacional Federation of Accountants. Internacional framework: good governance in the public sector. 2014.

JENSEN, Michael C.; MECKLING, William H. Theory of the firm: Managerial behavior, agency costs and ownership structure. Journal of financial economics, v. 3, n. 4, p. 305-360, 1976.

MATIAS-PEREIRA, José. Curso de administração pública: foco nas instituições e ações governamentais. In: Curso de Administração Pública: Foco nas Instituições e Ações Governamentais. 2010. p. 263-263.

MENDES, Marcos; ROCHA, C. Alexandre A. O que reelege um prefeito? Senado Federal, Consultoria Legislativa, 2004.

MENEGUIN, Fernando B.; BUGARIN, Maurício S.; CARVALHO, Alexandre X. de. O que leva um governante à reeleição? 2005.

NORDHAUS, William D. The political business cycle. The review of economic studies, v. 42, n. 2, p. 169-190, 1975.

NOVAES, Lucas; MATTOS, Enlinson. O efeito da intenção de reeleição sobre gastos em saúde: uma análise com base no modelo de reputação política. Revista de Economia Política, v. 30, n. 1, p. 140-158, 2010.

OCDE - Organização para a Cooperação e Desenvolvimento Econômico. OCDE Guidelines on corporate governance of state-owned enterprises. Organization for economic co-operation and development. 2015.

OLIVEIRA, Antonio Gonçalves; PISA, Beatriz Jackiu. IGovP: índice de avaliação da governança públicainstrumento de planejamento do Estado e de controle social pelo cidadão. Revista de Administração Pública, v. 49, n. 5, p. 1263-1290, 2015.

PELTZMAN, Sam. Voters as fiscal conservatives. The Quarterly Journal of Economics, v. 107, n. 2, p. 327-361, 1992.

ROGOFF, Kenneth. Equilibrium political budget cycles. The American Economic Review, n. 80, 1990. 
SECCHI, Leonardo. Modelos organizacionais e reformas da administração pública. Revista de Administração Pública, Rio de Janeiro, v. 43, n. 2, p. 347-369, 2009.

SILVA, Felipe de Figueiredo; BRAGA, Marcelo José. Determinantes da Reeleição Municipal da Bahia para o Período de 2000 a 2008. Planejamento e Políticas Públicas, n. 40, 2013.

SPECK, Bruno Wilhelm; CERVI, Emerson Urizzi. Dinheiro, Tempo e Memória Eleitoral: Os mecanismos que levam ao voto nas eleições para prefeito em 2012. Revista Dados, v. 59, n. 1, 2016.

STRANZ; E.; ALENCAR, A. A.; KREBS, J. BOSSELI, G. Estudo sobre os determinantes na reeleição de prefeitos: pleitos de 2000 e 2004. Confederação Nacional dos Municípios, 2008.

TCU - Tribunal de Contas da União. Referencial básico de governança aplicada a órgãos e entidades da administração pública. Brasília: TCU. Secretaria de Planejamento, Governança e Gestão, 2014.

WOOLDRIDGE, Jeffrey M. Introdução à econometria: uma abordagem moderna. Pioneira Thomson Learning, 2006.

\section{APÊNDICE}

Analisando-se as estatísticas das variáveis contínuas (exceto o IGM) dos modelos 1, 2 e 3, mostradas, respectivamente, nas Tabelas 5, 6 e 7, nota-se que são assimétricas e que têm peso nas caudas (média distinta da mediana e no caso da população, além disso, desvio padrão maior que a média).

Tabela 5: Estatísticas descritivas das variáveis contínuas originais do modelo $1(\mathrm{~N} 1=525)$

\begin{tabular}{llllll}
\hline Variável & Média & Mediana & Desvio-padrão & Assimetria & Curtose \\
\hline IGM & 0,478 & 0,475 & 0,064 & 0,251 & $-0,125$ \\
Força eleitoral & 55,39 & 54,00 & 11,50 & 1,535 & 4,929 \\
PIB per capita & 10,46 & 7,78 & 10,42 & 6,445 & 66,329 \\
População & 29754 & 10382 & 124090,68 & 16,163 & 310,382 \\
\hline
\end{tabular}

Fonte: Elaboração dos autores a partir de dados obtidos nos sítios do CFA, TSE e IBGE.

Tabela 7: Estatísticas descritivas das variáveis contínuas originais do modelo $3(\mathrm{~N} 3=417)$

\begin{tabular}{llllll}
\hline Variável & Média & Mediana & Desvio-padrão & Assimetria & Curtose \\
\hline IGM & 0,478 & 0,475 & 0,064 & 0,251 & $-0,125$ \\
Força eleitoral & 55,39 & 54,00 & 11,50 & 1,535 & 4,929 \\
PIB per capita & 10,46 & 7,78 & 10,42 & 6,445 & 66,329 \\
População & 29754 & 10382 & 124090,68 & 16,163 & 310,382 \\
\hline
\end{tabular}

Fonte: Elaboração dos autores a partir de dados obtidos nos sítios do CFA, TSE e IBGE.

Contudo, a transformação logarítmica daquelas variáveis possibilitou a obtenção de uma distribuição simétrica e a minimização dos pesos das causas, como pode ser constatado analisando-se a assimetria e a curtose dos dados expostas nas Tabelas 8, 9 e 10.

Tabela 8: Estatísticas descritivas das variáveis contínuas transformadas do modelo $1(\mathrm{~N} 1=525)$

\begin{tabular}{llllll}
\hline Variável & Média & Mediana & Desvio-padrão & Assimetria & Curtose \\
\hline $\ln$ (Força eleitoral) & 3,995 & 3,990 & 0,195 & 0,231 & 2,695 \\
$\ln$ (PIB per capita) & 2,136 & 2,052 & 0,577 & 1,117 & 1,895 \\
$\ln$ (População) & 9,385 & 9,248 & 1,059 & 1,128 & 2,029 \\
\hline
\end{tabular}


Fonte: Elaboração dos autores a partir de dados obtidos nos sítios eletrônicos do TSE e do IBGE.

Tabela 9: Estatísticas descritivas das variáveis contínuas transformadas do modelo $2(\mathrm{~N} 2=248)$

\begin{tabular}{llllll}
\hline Variável & Média & Mediana & Desvio-padrão & Assimetria & Curtose \\
\hline $\ln$ (Força eleitoral) & 4,010 & 4,000 & 0,229 & 0,858 & 1,338 \\
$\ln$ (PIB per capita) & 2,119 & 2,053 & 0,540 & 0,866 & 0,931 \\
$\ln$ (Populaçăo) & 9,377 & 9,162 & 1,071 & 1,189 & 1,704 \\
$\ln$ (Gasto) & $-1,018$ & $-0,889$ & 0,725 & $-0,867$ & 0,814 \\
\hline
\end{tabular}

Fonte: Elaboração dos autores a partir de dados obtidos nos sítios eletrônicos do TSE e do IBGE.

Tabela 10: Estatísticas descritivas das variáveis contínuas transformadas do modelo $3(\mathrm{~N} 3=424)$

\begin{tabular}{llllll}
\hline Variável & Média & Mediana & Desvio-padrão & Assimetria & Curtose \\
\hline $\ln$ (Força eleitoral) & 3,988 & 3,983 & 0,193 & 0,140 & 2,835 \\
$\ln$ (PIB per capita) & 2,142 & 2,071 & 0,587 & 1,054 & 1,772 \\
$\ln$ (População) & 9,417 & 9,261 & 1,041 & 0,995 & 1,190 \\
\hline
\end{tabular}

Fonte: Elaboração dos autores a partir de dados obtidos nos sítios eletrônicos do TSE e do IBGE.

As estatísticas descritivas das variáveis categóricas dos modelos 1, 2 e 3 são mostradas, respectivamente, nas Tabelas 11, 12 e 13.

Tabela 11: Estatísticas descritivas das variáveis categóricas do modelo $1(\mathrm{~N} 1=525)$

\begin{tabular}{|c|c|c|c|c|}
\hline \multicolumn{5}{|c|}{ Possibilidade de reeleição } \\
\hline & Frequência & $\%$ & $\begin{array}{l}\text { Frequência } \\
\text { acumulada }\end{array}$ & $\begin{array}{l}\% \\
\text { acumulada }\end{array}$ \\
\hline $1^{\circ}$ mandato & 424 & 80,1 & 424 & 80,1 \\
\hline $2^{\circ}$ mandato & 101 & 19,9 & 101 & 100 \\
\hline \multicolumn{5}{|c|}{ Partido governador/presidenta } \\
\hline $\begin{array}{l}\text { Filiado ao } \\
\text { PT }\end{array}$ & 24 & 4,6 & 24 & 4,6 \\
\hline $\begin{array}{l}\text { Não filiado } \\
\text { ao PT }\end{array}$ & 501 & 95,4 & 525 & 100 \\
\hline
\end{tabular}

Fonte: Elaboração dos autores a partir de dados obtidos no sítio eletrônico do TSE. 
Tabela 12: Estatísticas descritivas das variáveis categóricas do modelo $2(\mathrm{~N} 2=248)$

\begin{tabular}{lllll}
\hline Reeleição & & & & \\
\hline & Frequência & $\%$ & $\begin{array}{l}\text { Frequência } \\
\text { acumulada }\end{array}$ & $\begin{array}{l}\text { \% } \\
\text { acumulada }\end{array}$ \\
\hline $\begin{array}{l}\text { Não reeleito } \\
\text { Reeleito }\end{array}$ & 127 & 51,2 & 127 & 51,2 \\
\hline Partido & 121 & 48,8 & 248 & 100 \\
\hline $\begin{array}{l}\text { Não filiado ao } \\
\text { PT }\end{array}$ & 233 & 94,0 & 233 & 94,0 \\
Filiado ao PT & 15 & 6,0 & 248 & 100 \\
\hline $\begin{array}{l}\text { Não filiado ao } \\
\text { PMDB }\end{array}$ & 191 & 77,0 & 191 & 77,0 \\
$\begin{array}{l}\text { Filiado ao } \\
\text { PMDB }\end{array}$ & 57 & 23,0 & 248 & 100 \\
\hline $\begin{array}{l}\text { Não filiado ao } \\
\text { PSDB }\end{array}$ & 211 & 85,1 & 211 & 85,1 \\
$\begin{array}{l}\text { Filiado ao } \\
\text { PSDB }\end{array}$ & 37 & 14,9 & 248 & 100 \\
\hline
\end{tabular}

Fonte: Elaboração dos autores a partir de dados obtidos no sítio eletrônico do TSE.

Tabela 13: Estatísticas descritivas das variáveis categóricas do modelo $3(\mathrm{~N} 3=424)$

\begin{tabular}{lllll}
\hline \multicolumn{2}{c}{ Candidatura à reeleição } & & & \\
\hline & Frequência & $\%$ & $\begin{array}{l}\text { Frequência } \\
\text { acumulada }\end{array}$ & $\begin{array}{l}\text { \% } \\
\text { acumulada }\end{array}$ \\
\hline $\begin{array}{l}\text { Não } \\
\text { Candidatou }\end{array}$ & 168 & 39,6 & 168 & 39,6 \\
Candidatou & 256 & 60,4 & 424 & 100 \\
\hline
\end{tabular}

Fonte: Elaboração dos autores a partir de dados obtidos no sítio eletrônico do TSE.

\section{BY-NC-ND}

